\title{
El programa PROTODEBA v. 1.0: \\ una proposta per a l'observació \\ de la presa de decisions en handbol
}

\author{
The PROTODEBA V1.0 Program: A Proposal for the Observation \\ of Decision-Making in Handball
}

\author{
IGNACIO MARTÍN TAMAYO \\ Departament de Metodologia de les Ciències del Comportament \\ Universidad de Granada
}

LUIZ ARTHUR CAVALCANTI CABRAL

Departament de Educació Física

UNIPÊ: Centro Universitário de João Pessoa (Brasil)

\section{LUIS JAVIER CHIROSA RÍOS}

JAVIER AGUILAR SÁNCHEZ

Departament d'Educació Física i Esportiva

Universidad de Granada

Autor per a la correspondència

Ignacio Martín Tamayo

imartin@ugr.es

\section{Resum}

La presa de decisions constitueix un aspecte clau en el rendiment de qualsevol esport col·lectiu. En aquest article es presenta el programa PROTODEBA v. 1.0, desenvolupat per a l'estudi i anàlisi de la presa de decisions analítiques d'un equip d'handbol i dels jugadors en les diferents seqüències d'atac. El programa permet observar els comportaments dels jugadors en tres categories observacionals: ubicació, trasllat i finalització, que proporcionen índexs de participació i de presa de decisions per a l'equip en el seu conjunt, per a cada jugador i per a les diferents seqüències d'un partit. A més, es presenta un exemple de l'aplicació del programa informàtic en un partit d'handbol d'alt nivell.

Paraules clau: presa de decisions, handbol, metodologia observacional, rendiment

\begin{abstract}
The PROTODEBA V1.0 Program: A Proposal for the Observation of Decision-Making in Handball

Decision-making is a key aspect in performance in any team sport. In this paper we present the PROTODEBA $v 1.0$ program, developed for the study and analysis of the analytical decision-making of a handball team and its players in different attack sequences. The program makes it possible to observe the behaviour of players in three observational categories, namely location, transfer and termination, providing participation and decision-making rates for the team as a whole, for each player and for the various sequences in a game. It also presents an example of the implementation of the software in a high-level handball game.
\end{abstract}

Keywords: decision-making, handball, observational methods, performance

\section{Introducció}

En l'esport adquireix una especial rellevància l'ús d'indicadors per avaluar el rendiment dels esportistes o d'un equip. Dues disciplines han utilitzat aquest tipus d'indicadors: per una banda, la biomecànica i, per l'altra, l'anàlisi observacional. Mentre que la primera s'ha concentrat en l'estudi del rendiment en esports en els quals la tècnica o habilitats tancades tenen una crucial rellevància, l'anàlisi observacional s'ha centrat en els esports d'equip estudiant les interaccions entre els jugadors i els seus moviments o conductes. Els indicadors que s'han utilitzat en l'anàlisi observacional poden classificar-se en indicadors de puntuació (per exemple, gols, cistelles, cops guanyadors, llançaments 
a porta, etc.) o indicadors qualitatius (per exemple: pèrdues, placatges, passades/possessió, etc.) (Hughes \& Bartlett, 2002).

Tanmateix, s'han desenvolupat pocs sistemes d'observació per avaluar aspectes tàctics i, en concret, sobre la presa de decisions (Kuehl-Kitchen, 2005; Panton, 2006). A causa d'això, escassos instruments avaluen les situacions reals de joc i els comportaments de tots els jugadors (amb i sense possessió de la pilota), essent els jugadors no posseïdors de la pilota essencials per a l'èxit en qualsevol esport col·lectiu (Mitchell \& Griffin, 1994). En aquests, l'exigència decisional (Ruiz \& Arruza, 2005) i les adaptacions a l'entorn canviant on es desenvolupen (Iglesias, 2005) són dues de les diferències fonamentals amb altres esports.

Des de l'àrea de l'ensenyament de l'esport repetidament s'ha intentat mesurar comportaments que impliquen coneixement tàctic. Una primera aproximació va ser la proposta per Grehaigne, Godbout i Bouthier (1997) de desenvolupar un sistema observacional per a l'avaluació (formativa i sumativa en contextos esportius reals) d'esports d'equip: Team Sport Perfomance Assessment (TSAP). El sistema està basat en l'observació dels jugadors mitjançant una avaluació de pares fonamentat en dues qüestions bàsiques: $a$ ) com el jugador aconsegueix la possessió? (per exemple, conquesta de la pilota mitjançant la recepció de la passada d'un company) i $b$ ) què fa amb la pilota? (per exemple, passa la pilota, dispara o la perd). D'acord amb aquestes qüestions, les conductes dels jugadors són observades i registrades en sis components -conquesta la pilota (CP), rep la pilota (RP), juga de forma neutral (NP), perd la pilota (LP), juga la pilota ofensivament (P) i efectua un llançament exitós (SS)- amb l'objectiu de reflectir l'execució en atac dels jugadors en jocs d'invasió. En funció d'aquests components, van definir tres índexs: volum de joc (VP), índex d'eficiència (EI) i, a partir d'aquests, la puntuació en execució (PS).

$$
\begin{gathered}
V P=C P+R P \\
E I=\frac{(C P+P+S S)}{(10+L P)} \\
P S=\frac{V P}{2}+(E I \cdot 10)
\end{gathered}
$$

Una proposta posterior en aquest àmbit va ser la d'Oslin, Mitchell i Griffin (Oslin, Mitchell, \& Griffin, 1998; Mitchell, Oslin, \& Griffin, 2006): The
Game Performance Assessment Instrument (GPAI). Aquest instrument observacional permet codificar les conductes dels jugadors relacionades amb la solució de problemes tàctics. Les conductes a observar es poden establir en set components: base, ajust, presa de decisions, execució tècnica, suport, cobertura i guàrdia/marca.

Encara que tots els components estan relacionats amb el rendiment en el joc, no s'apliquen a tots els esports, i poden simplificar-se en determinats contextos. Per exemple, per al futbol es poden aplicar tots excepte el component denominat base. Per tant, l'observació se centra en un jugador i registra en cada component elegit el nombre de respostes apropiades-eficients, per una banda, i el nombre de respostes inapropiades-ineficients, per una altra. Mitchell, Oslin i Griffin (2006) proposen els índexs de mesura del GPAI tenint en compte l'avaluació dels següents elements: la presa de decisions apropiades o inapropiades $(\mathrm{Da}, \mathrm{Di})$, les habilitats d'execució efectives o inefectives (HEe, HEi) i els suports apropiats o inapropiats $(\mathrm{Sa}, \mathrm{Si})$. En funció d'aquests elements, defineixen els següents índexs en cada component: índex de decisions (ID), índexs d'habilitat en execució (IHE), índex de suport (IS) i els índexs globals de participació en el joc (PJ) i de rendiment en el joc (RJ):

$$
\begin{gathered}
I D=\frac{D a}{(D a+D i)} \\
I H E=\frac{H E e}{(H E e+H E i)} \\
I S=\frac{A a}{(S a+S i)} \\
P J=D a+D i+H E e+H E i+S a \\
R J=\frac{(I D+I H E+I S)}{3}
\end{gathered}
$$

Recentment, Memmert i Harvey (2008) han posat de manifest alguns problemes de codificació i càlcul amb els índexs anteriorment descrits. Dos d'aquests són els problemes principals. En primer lloc, en el càlcul dels índexs de cada component, si un jugador no mostra conductes apropiades, independentment del nombre de conductes inapropiades que s'hagin registrat, l'índex serà igual a zero. Així, dos subjectes amb conductes inapropiades, un amb dos i un altre amb vint, tindran un índex de zero encara 
que la seva valoració hauria de ser diferent. En segon lloc, l'índex global RJ no pot estar valorat solament, ja que un jugador que tingui poques però les mateixes conductes apropiades $\mathrm{i}$ inapropiades que un altre que tingui moltes conductes però la mateixa proporció que l'anterior de respostes apropiades i inapropiades obtindrà el mateix valor de RJ. "Basar-se solament en l'ús de l'índex RJ, sense fer referència a l'índex PJ, pot donar una falsa lectura del nombre d'interaccions de cada jugador durant el joc" (Memmert \& Harvey, 2008, p. 231).

\section{El sistema observacional}

Enfront a aquests instruments es va decidir realitzar un sistema observacional, centrat fonamentalment en la presa de decisions en handbol, que es plasmaria en un programa informàtic. Per abordar-lo es va acordar, en principi, centrar-nos en les decisions analítiques dels jugadors en el partit. Ja que l'àrea a estudiar és extensa i complexa es van fer posar algunes limitacions. En primer lloc, seleccionar les seqüències d'atac, és a dir, només s'estudiaran els jugadors que ataquen la porteria rival. En segon lloc, només es tindran en compte seqüències en les quals es comença amb una posició en atac posicional dels sis jugadors, per tant, s'exclou el porter en aquest estudi i, a més, queden fora les seqüències com els contraatacs.

Seguint els criteris proposats per Anguera (1999), es va desenvolupar una eina observacional en la qual la unitat bàsica d'observació, que anomenem moment, es defineix com l'espai temporal transcorregut entre que un jugador A té la pilota i la passa (i és rebut per un altre jugador B del seu equip), o la llança o en perd la possessió. Els moments s'agrupen en seqüències de joc, des que comença un atac posicional fins que aquest finalitza quan l'equip que té la possessió de la pilota la perd per algun motiu (llançament, pèrdua o falta assenyalada per l'àrbitre).

Es van establir tres categories d'observació en les quals cada jugador d'atac era valorat $(\mathrm{amb}-1,0,+1)$ en cada moment. Les categories van ser denominades de la següent manera: ubicació, trasllat, finalització. Es defineixen a continuació:

- Ubicació: Es defineix com la influència del lloc concret que ocupa un jugador tenint en compte la seva situació, posició i intenció. La valoració és la següent:
- -1: El jugador no té una correcta posició, situació i intenció o comet un error de reglament (invasió, falta d'atac, etc.).

- 0: El jugador compleix amb alguna de les subcategories (posició, situació i intenció). Si passa o llança la pilota. Es troba fora de la zona de $9 \mathrm{~m}$.

- 1: El jugador té una correcta posició, situació i intenció. Es troba dins la zona de $9 \mathrm{~m}$.

- Trasllat: Totes les accions de desplaçament que es produeixen durant el moment tant del portador de la pilota com dels seus companys.

- -1: El jugador no va a l'espai lliure de marcatge. No fixa més d'un defensor o bota sense necessitat. Comet algun error de reglament.

- 0: El jugador, amb el seu desplaçament, no obté avantatge per a l'atac, ni perjudica la defensa. No es desplaça (amb o sense pilota).

- 1: El jugador va a l'espai lliure de marcatge amb situació d'èxit: 1r guanyar angle, $2 \mathrm{n}$ guanyar espai per a un altre jugador o per a ell mateix. Fixa més d'un defensor.

- Finalització: Acció que es valora quan el portador es desprèn definitivament de la pilota. Per tant, està relacionada només amb la persona que té la pilota (els altres jugadors són qualificats com a neutres). Tres opcions: a) llançament: és l'acció de projectar la pilota fins a la porteria; b) passada: l'acció de traslladar la pilota a un company, i $c$ ) error: quan es perd la pilota per incompliment de reglament o recuperació contrària.

- -1 : El jugador falla la passada o llança fora de porteria o comet algun error de reglament.

- 0: La passada no influeix en l'acció ofensiva o el llançament va a porteria i no entra amb o sense parada del porter.

- 1: El jugador passa la pilota creant així una clara situació de llançament o una situació de superioritat numèrica en atac. Quan el llançament és gol.

El procediment seguit fins a la depuració de les categories i criteris de valoració va ser la següent. Després de les decisions que van prendre els investigadors sobre la definició de constructe, les acotacions que s'hi van fer així com les precisions sobre els paràmetres temporals, es va realitzar un primer 
protocol amb instruccions per als observadors i un full d'anotació de resultats en paper. Seguint la proposta de seqüència i procediments per a la validesa de contingut recomanada per Haynes, Richard i Kubany (1995), es va administrar aquest protocol a cinc experts en handbol individualment $i$, posteriorment, es van reunir en diferents sessions segons la tècnica de Grup Focal (Morgan, 1996, 1997) en la qual va fer de moderador l'investigador principal, expert en handbol, en observació i en investigació. En aquestes reunions es va discutir i es va consensuar el constructe, les dimensions i les definicions d'aquest i la unitat d'observació, i es van examinar també els aspectes relatius a les instruccions i el format de resposta.

Les modificacions es van dirigir principalment a les definicions de cada dimensió i també a les categories d'observació que van passar de dos $\left(\begin{array}{lll}0 & \mathrm{i} & 1\end{array}\right)$ a tres $(-1,0 \mathrm{i}+1)$. Es va posar de manifest la necessitat d'automatitzar l'observació, ja que en les proves pilot es va constatar que aquesta manera de registrar era laboriosa i que l'observador cometia alguns errors ja que havia d'indicar molta informació en poc espai i, a més, es trigava molt a llegir el registre complet de diverses seqüències. Per tant, es va arribar a la conclusió que era important automatitzar l'eina.

Amb les modificacions aportades, es va idear un programa informàtic, creant, d'aquesta manera, el software PROTODEBA v. 1.0 i es van adaptar les instruccions $\mathrm{i}$ les modificacions derivades de la fase anterior. Novament, cada expert va realitzar una observació de seqüències de joc i es van produir un segon conjunt de reunions amb l'objectiu d'analitzar i depurar l'eina observacional informatitzada. Es va constatar la millora en la velocitat i la precisió de les observacions, i tan sols es van introduir lleus modificacions relatives a la definició dels criteris de valoració en cada categoria o dimensió observacional. Les apreciacions es van fer amb l'objectiu de diferenciar, encara més, les categories d'observació dins cada dimensió.

\section{El programa PROTODEBA v. 1.0}

Aquest programa ha estat desenvolupat en una plataforma de 32 bits mitjançant el llenguatge de programació Microsoft Visual Basic 6.0 i utilitzant la base de dades de codi obert Firebird 2.0. PROTODEBA v. 1.0 permet valorar les tres dimensions de cada jugador de camp (sis, amb excepció del porter) en cada moment de joc, ja que disposa d'una finestra en la qual funciona el reproductor Windows Media i que permet visualitzar el vídeo mentre que l'observador registra les dades (fig. 1).

\section{Índexs PROTODEBA v. 1.0}

En el nostre cas, cal ressaltar que es van mesurar en cada moment $(\mathrm{m})$ tres categories $(\mathrm{c})$ : ubicació $(\mathrm{u})$, trasllat (t) i finalització (f) a cada jugador -sis jugadors

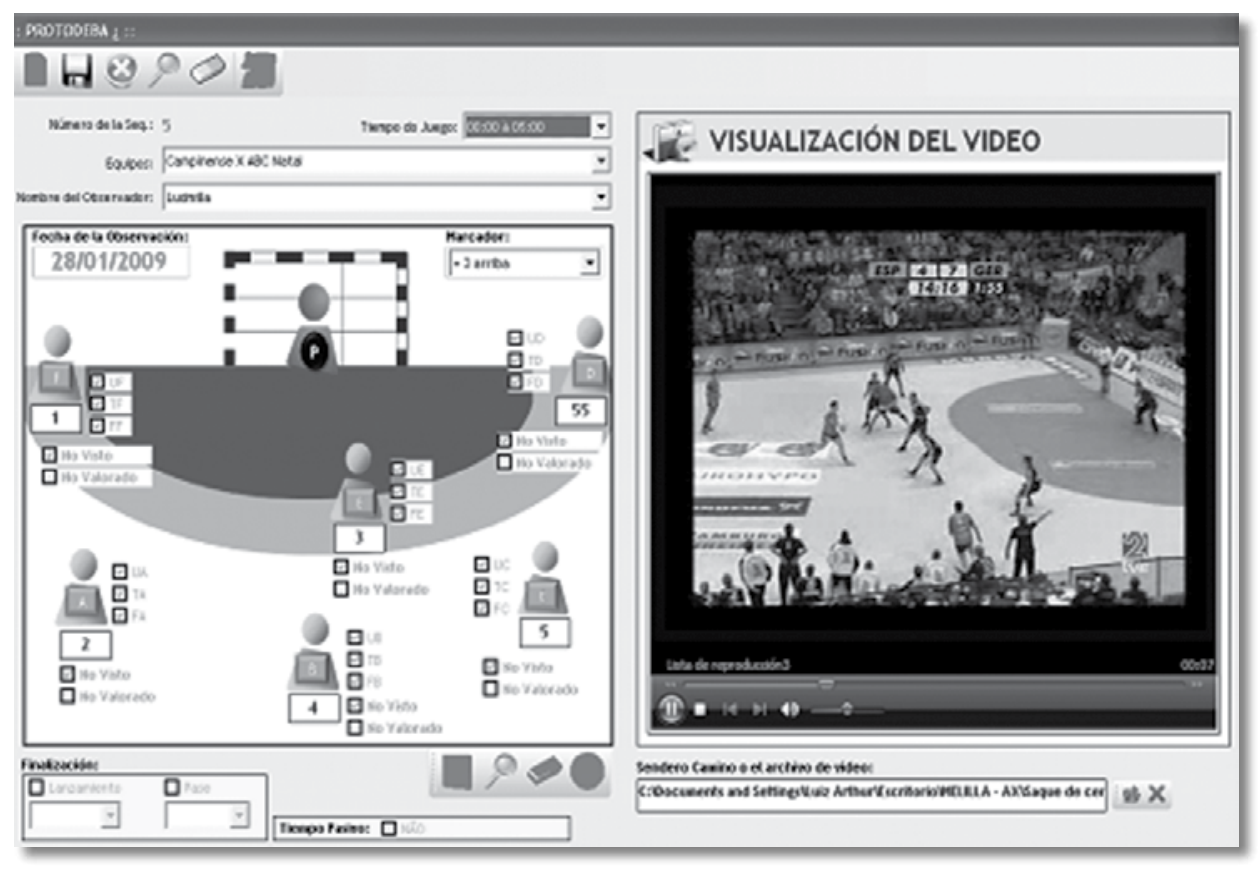

$\checkmark$

Figura 1

Visualització del programa PROTODEBA v. 1.0 
de camp (J)-. De la mateixa manera, els moments es van agrupar en seqüències de joc (s). També cal ressenyar que la valoració es va fer en una escala amb tres valors (V) $-1,0$ i +1 . Així, els índexs que es proposen en són dos: la presa de decisions (IPD) i d'implicació o participació (IP). L'IPD suma totes les valoracions $(1,0$ i -1) directament, mentre que l'IP suma el valor absolut d'aquestes valoracions.

Per a un partit donat es tindrien els següents índexs globals:

$$
\begin{gathered}
I P D_{\text {partit }}=\left[\frac{\sum_{j=1}^{6} \sum_{c=1}^{3} \sum_{s=1}^{\mathrm{k}} \sum_{\mathrm{m}=1}^{h} V_{j c s m}}{6 \cdot 3 \cdot\left(\sum_{s=1}^{k} \sum_{m=1}^{h} m_{s m}\right)}\right] \cdot 100 \\
I P D_{\text {partit }}=\left[\frac{\sum_{j=1}^{6} \sum_{c=1}^{3} \sum_{s=1}^{k} \sum_{m=1}^{h}\left|V_{j c s m}\right|}{6 \cdot 3 \cdot\left(\sum_{s=1}^{k} \sum_{m=1}^{h} m_{s m}\right)}\right] \cdot 100
\end{gathered}
$$

Els índexs per a cada categoria es presenten a continuació:

$$
\begin{aligned}
I P D_{c} & =\left[\frac{\sum_{j=1}^{6} \sum_{s=1}^{k} \sum_{m=1}^{h} V_{j s m}}{6 \cdot\left(\sum_{s=1}^{k} \sum_{m=1}^{h} m_{s m}\right)}\right] \cdot 100 \\
I P_{c} & =\left[\frac{\sum_{j=1}^{6} \sum_{s=1}^{k} \sum_{m=1}^{h}\left|V_{j s m}\right|}{6 \cdot\left(\sum_{s=1}^{k} \sum_{m=1}^{h} m_{s m}\right)}\right] \cdot 100
\end{aligned}
$$

També es podria veure com han anat variant aquests índexs en cada seqüència:

$$
\begin{gathered}
I P D_{s}=\left[\frac{\sum_{j=1}^{6} \sum_{c=1}^{3} \sum_{m=1}^{h} V_{j c m}}{6 \cdot 3 \cdot\left(\sum_{m=1}^{h} m_{m}\right)}\right] \cdot 100 \\
I P_{S}=\left[\frac{\sum_{j=1}^{6} \sum_{c=1}^{3} \sum_{m=1}^{h}\left|V_{j c m}\right|}{6 \cdot 3 \cdot\left(\sum_{m=1}^{h} m_{m}\right)}\right] \cdot 100
\end{gathered}
$$

Igualment, s'obtenen els índexs per a cada jugador:

$$
\begin{gathered}
I P D_{j}=\left[\frac{\sum_{c=1}^{3} \sum_{s=1}^{k} \sum_{m=1}^{h} V_{c s m}}{3 \cdot\left(\sum_{s=1}^{k} \sum_{m=1}^{h} m_{s m}\right)}\right] \cdot 100 \\
I P_{j}=\left[\frac{\sum_{c=1}^{3} \sum_{s=1}^{k} \sum_{m=1}^{h}\left|V_{c s m}\right|}{3 \cdot\left(\sum_{s=1}^{k} \sum_{m=1}^{h} m_{s m}\right)}\right] \cdot 100
\end{gathered}
$$

I per a cada jugador en cada categoria:

$$
\begin{gathered}
I P D_{j x c}=\left[\frac{\sum_{s=1}^{k} \sum_{m=1}^{h} V_{s m}}{\sum_{s=1}^{k} \sum_{m=1}^{h} m_{s m}}\right] \cdot 100 \\
I P_{j x c}=\left[\frac{\sum_{s=1}^{k} \sum_{m=1}^{h}\left|V_{s m}\right|}{\sum_{s=1}^{k} \sum_{m=1}^{h} m_{s m}}\right] \cdot 100
\end{gathered}
$$

Els índexs de presa de decisions tenen un rang de valors entre $-100 \mathrm{i}+100$, mentre que els índexs de participació varien entre 0 i 100.

\section{Exemple}

En un partit d'handbol entre Puente Genil i Puertollano de la primera divisió nacional espanyola es van observar setanta-tres seqüències de joc d'atac posicional. Cada una d'aquestes comprenia entre un i set moments. En total es van establir 251 moments, és a dir, 4.518 observacions (encara que cal restar aquelles en les quals no s'ha realitzat l'observació per no veure's els jugadors en el vídeo, que en el nostre exemple ascendeixen a 389).

Els resultats que presenten els índexs per al partit van ser:

$$
\begin{aligned}
I P D_{\text {partit }} & =\left[\frac{152}{4129}\right] \cdot 100=3,68 \\
I P_{\text {partit }} & =\left[\frac{347}{4129}\right] \cdot 100=8,40
\end{aligned}
$$

És difícil interpretar aquests índexs per a un únic partit. Amb aquests obtindrem un major valor imperatiu quan puguem comparar-los amb els obtinguts en altres partits, que ens poden indicar el grau de participació del nostre equip (segons l'IP) i si aquesta participació ens ha portat a bones o males decisions en comparació amb altres partits en funció d'ITD.

Igualment el programa proporciona els índexs de l'equip, però a cada categoria. En aquest partit els resultats obtinguts per a l'índex de participació (IP) presenten els seus valors majors en la categoria de trasllat $(11,04)$, i els seus valors menors en la categoria de finalització $(3,77)$. D'altra banda, l'índex de presa de decisions (IPD) presenta els majors valors en la categoria d'ubicació $(5,22)$ i els menors corresponen a la categoria de finalització $(1,19)$. Per tant, en la categoria de finalització és on es troben els menors valors per a ambdós índexs. A més, també és destacable que la categoria de trasllat presenta els valors més alts en la participació en el joc (IP) i valors baixos en la presa de decisions (IPD), per la qual cosa malgrat ser la categoria amb més participació, no és la categoria amb major nombre de decisions encertades.

D'altra banda, es van calcular els índexs per a les setanta-tres seqüències, en què s'obtingués un valor màxim de 13,89 , un valor mínim de $-12,96$ en l'índex 
de presa de decisions (IPD); un valor màxim de 18,52, i un valor mínim de 0 en l'índex de participació (IP).

En la figura 2 es pot apreciar com l'equip ha anat desenvolupant el joc quant a la participació i a la presa de decisions i comprar en cada seqüència ambdós índexs. Així, per exemple, es pot veure que entre les seqüències sis i nou hi ha una gran diferència entre la participació de l'equip i les decisions preses.

També es van calcular els índexs per jugador. Com es pot apreciar en la figura 3, les dades d'aquest partit mostren valors entre 0 i 32,5 en l'índex de presa de decisions (IPD) i entre 8,84 i 46,46 en l'índex

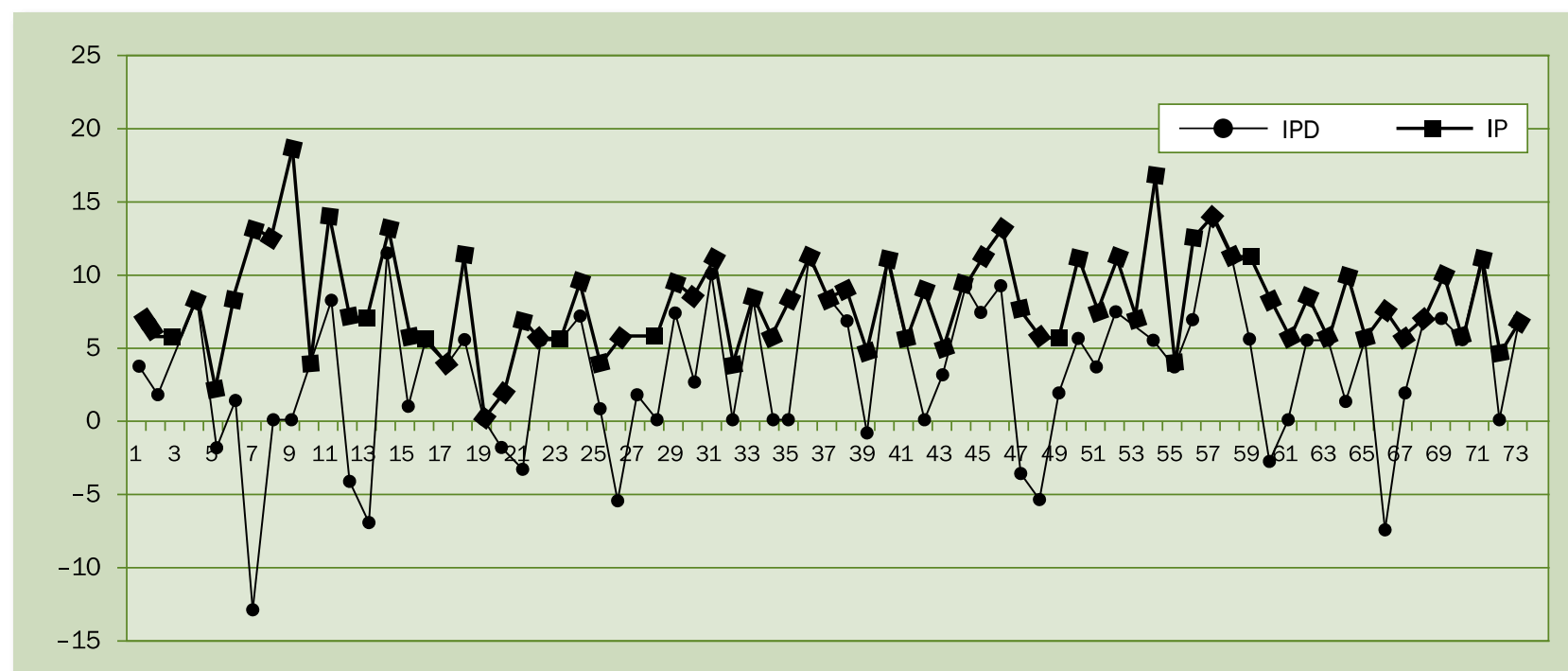

$\Delta$

Figura 2

Gràfic de l'índex de presa de decisions (IPD) i de l'índex de participació (IP) de l'equip en les setanta-tres seqüències del partit estudiades

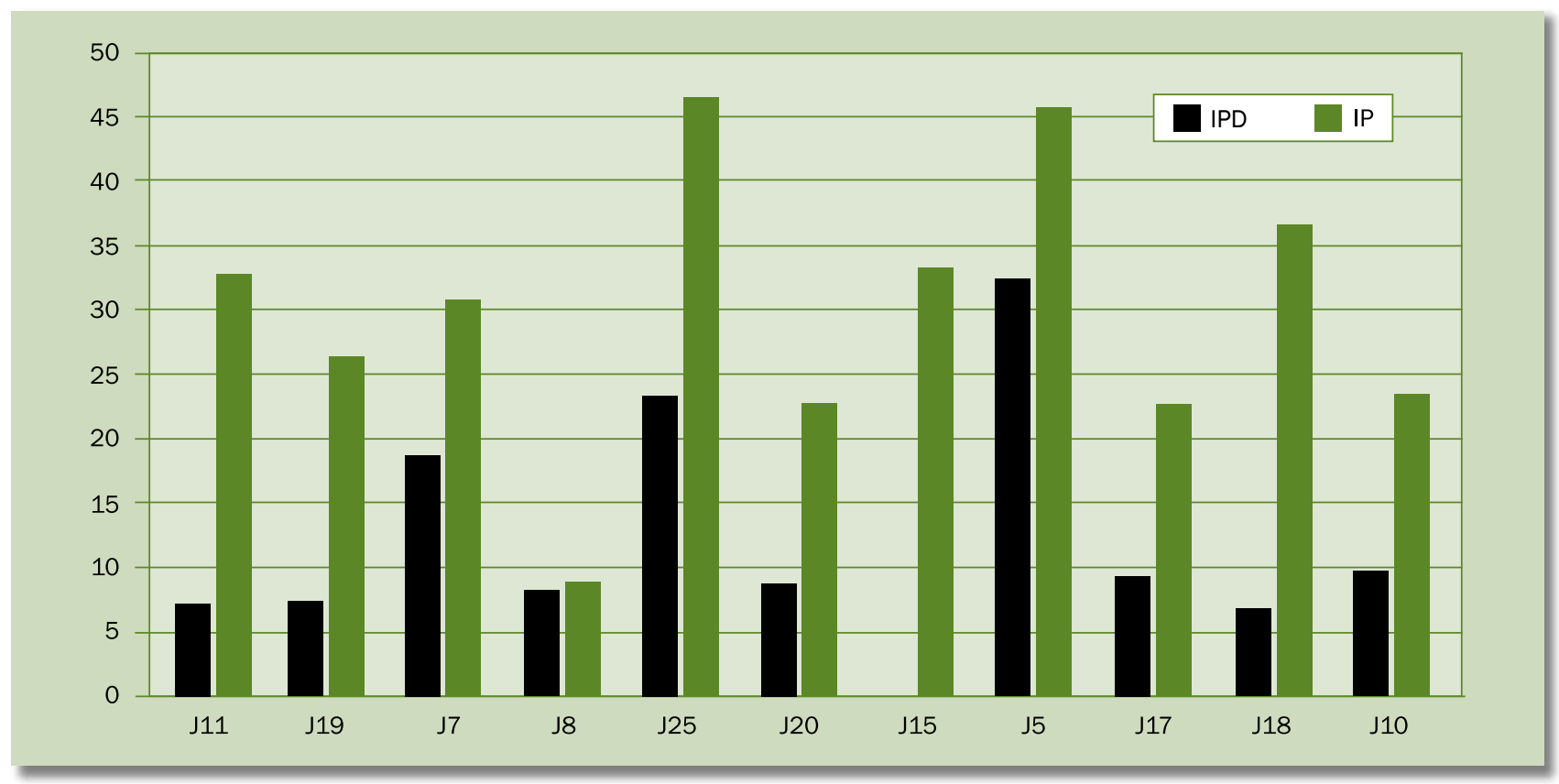

Figura 3

Gràfic de l'índex de presa de decisions (IPD) i de l'índex de participació (IP) de cada jugador 


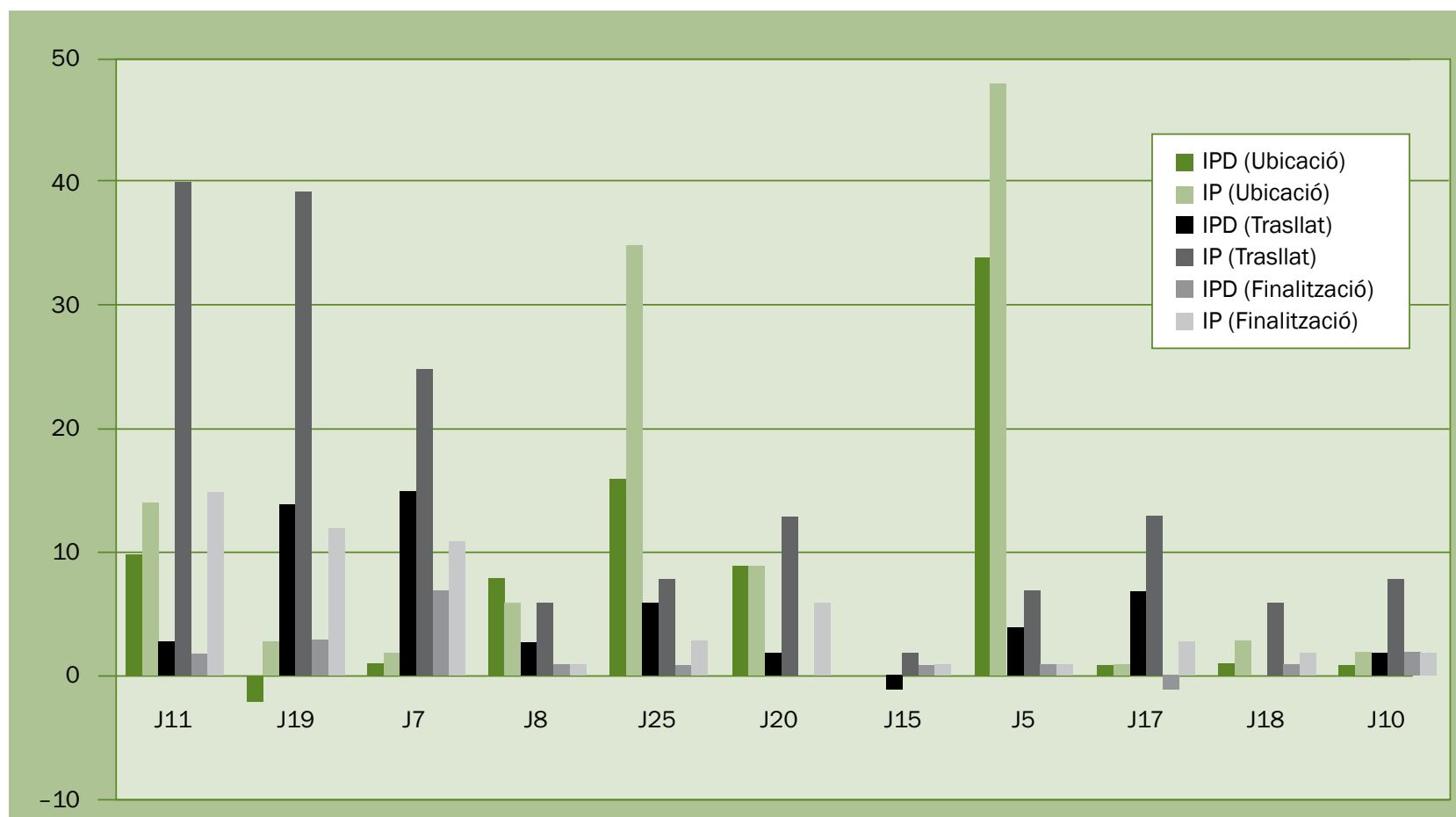

\section{Figura 4}

Gràfic de l'índex de presa de decisions (IPD) i de l'índex de participació (IP) de cada jugador en cada categoria

de participació en el joc (l'IPJ). El que més destaca són els comportaments del jugador 5 (J5), que presenta valors molt alts per a ambdós índexs. Pel contrari, el jugador 8 (J8) té valors baixos en els dos índexs, però cal dir que té un índex de presa de decisions (IPD) molt alt en comparació amb la seva participació en el joc (IP).

D'altra banda, en la figura 4 es poden veure els índexs per a cada jugador $i$ en cada categoria, i ens dóna una informació descriptiva, útil i completa de cadascú. El jugador 5 (J5) és el que posseeix els valors més alts en ambdós índexs per a la categoria d'ubicació. El jugador 11 (J11) té els valors més alts en l'índex de participació (IP) en la categoria de trasllat, presentant pel contrari valors baixos en l'índex de presa de decisions (IPD) per a la mateixa categoria. En la categoria de finalització, el jugador 7 (J7) presenta valors alts per als dos índexs. És destacable la presència de valors negatius per a alguns jugadors en l'índex de presa de decisions (IPD) en certes categories. Per exemple, el jugador 19 (J19) té valors negatius en l'índex de presa de decisions (IPD) en la categoria d'ubicació; el jugador 15 (J15), en la categoria de trasllat, i el 17 (J17), en la categoria de finalització.

\section{Discussió i conclusions}

Amb la creació del programa PROTODEBA v. 1.0 s'aconsegueix una eina que permet posar de manifest la presa de decisions en comparació amb la participació en el joc, dos aspectes bàsics per a l'estudi del rendiment de qualsevol esport col-lectiu. El programa permetrà reconèixer de manera real la relació entre el nombre d'accions en les quals participa un jugador i el seu grau d'eficàcia, evitant així el judici de valor subjectiu, molt influenciable per factors externs i inèdits (com pot ser l'espectacularitat d'una acció per part d'un jugador que, tanmateix, al llarg de tot el partit està prenent poques decisions encertades). Concretament, i com l'instrument dissenyat per Oslin, Mitchel i Griffin (1998), el programa ha estat creat per a l'avaluació de tots els jugadors (amb i sense possessió de la pilota) i ofer la possibilitat d'estudiar un equip en la seva totalitat o un jugador en concret en cada un dels aspectes considerats (ubicació, trasllat o finalització), per la qual cosa proporciona certa flexibilitat en funció dels objectius que es pretenen i, per tant, es poden adoptar estratègies per al compliment dels objectius esmentats. 
Un altre dels avantatges que presenta el programa és que està totalment automatitzat-informatitzat, cosa que permet agilitzar el treball tant en la introducció de les dades com en l'obtenció dels resultats. Evidentment, els observadors necessitaran, per obtenir precisió en les dades recollides, un exhaustiu entrenament (Medina \& Delgado, 1999).

De la mateixa manera, un altre avantatge en comparació amb altres sistemes, com el GPAI (Oslin et al., 1998) o el TSAP (Grehaigne, Godbout, \& Bouthier, 1997), és que en establir com a denominador en les avaluacions els moments, es poden comparar el índexs de diferents partits encara que en un s'hagin produit més moments que en un altre. Així, es podran realitzar comparacions entre jugadors, equips i/o partits, en funció dels interessos que tinguem.

El sistema també permet superar les limitacions apuntades per Memmert i Harvey (2008). En primer lloc, l'índex de presa de decisions (IPD) pot tenir valors negatius, zero o positius i els situa en relació amb el nombre de decisions encertades o errònies. Si, per exemple, un jugador pren més decisions errònies que adequades obtindrà valors negatius. D'altra banda, aquests índexs mostren la seva màxima potencialitat, com hem vist en els exemples, quan es relacionen. És molt interessant, doncs, comparar l'índex de presa de decisions (IPD) amb el de participació en el joc (IP), ja sigui en la seva globalitat, en les seqüències, en les categories, en el jugador, etc., i indicar la participació (com a aspecte quantitatiu), però també la qualitat d'aquesta participació (com a aspecte qualitatiu). En definitiva, és una eina que de manera gràfica $\mathrm{i}$ simple li dóna informació a l'entrenador i redueix la incertesa sobre les preses de decisions estratègiques que s'han de prendre.

Pel contrari, el desavantatge enfront dels mètodes TSAP i GPAI és que el procediment, malgrat estar informatitzat, requereix d'un observador entrenat per fer-ho, per la qual cosa es dirigeix fonamentalment a estudiar el rendiment en situacions d'alt nivell més que en situacions d'aprenentatge o de formació de jugadors, on els sistemes anteriorment esmentats (TSAP y GPAI) eren els més utilitzats (Harvey, 2003; Harvey, 2006; Hooper, 2007; Panton, 2006; Mitchell, Oslin, \& Griffin, 1995; Martin, 2004; Kirkwood, 2007).

\section{Referències}

Anguera, M. T. (Coord.). (1999). Observación en deporte y conducta cinestésico-motriz: aplicaciones. Barcelona: Universitat de Barcelona.
Grehaigne, J. F., Godbout, P., \& Bouthier, D. (1997). Performance assessment in team sports. Journal of Teaching in Physical Education, 16(4), 500-516.

Harvey, S. (Desembre 2003). Teaching Games for Understanding: A Study of U19 College Soccer Player Improvement in Game Perfomance Using the Game Perfomance Assessment Instrument. Ponència presentada a la 2a Conferència Internacional "Teaching Sport and Physical Education for Understanding”, Melbourne, Austràlia.

Harvey, S. (2006). Effects of Teaching Games for Understanding on Game Performance and Understanding in Middle School Physical Education (Tesis doctoral). Oregon State University, Estats Units d'Amèrica.

Haynes, S. N., Richard, D. C. S., \& Kubany, E. S. (1995). Content validity in psychological assessment: A functional approach to concepts and methods. Psyhological Assessment, 7(3), 238-247. doi: $10.1037 / 1040-3590.7 .3 .238$

Hooper, T. (2007). Teaching tennis with assessment for/as learning: A TGfU net/wall example. Journal of Physical Health Education, 73(3), 1-11. doi:10.1037/1040-3590.7.3.238

Hughes, M. D. \& Bartlett R. M. (2002). The use of performance indicators in performance analysis. Journal of Sports Sciences, 20(10), 739-745.

Iglesias, D. (2005). Conocimiento táctico y toma de decisiones en la formación de jóvenes jugadores de baloncesto. Cáceres: CV Ciencias del Deporte.

Kirkwood, R. (2007). The relationship between tactical knowledge and tactical perfomance for varying levels of expertise (Tesis doctoral). University of Rhode Island, Estats Units d'Amèrica.

Kuehl-Kitchen, J. M. (2005). Pre-service teachers' experiences in planning, implementing and assessing the tactical (TGFU) model (Tesi doctoral), The Florida State University, Estats Units d'Amèrica.

Martin, R. J. (abril 2004). An Investigation of Tactical Transfer in Invasion/Territorial Games. Pòster presentat a AAHPERD National Convention and Exposition, Nueva Orleans, Estats Units d'Amèrica.

Medina, J. \& Delgado, M. A. (1999). Metodología de entrenamiento de observadores para investigaciones sobre Educación Física y Deporte en las que se utilice como método la observación. Motricidad, 5, 69-86.

Memmert, D. \& Harvey, S. (2008). The game performance assessment instrument (GPAI): Some concerns and solutions for further development. Journal of Teaching in Physical Education, 27(2), 220-240.

Mitchell, S. A. \& Griffin, L. L. (1994). Tactical awareness as a developmentally appropriate focus for the teaching of games in elementary and Secondary Physical Education. Physical Educator, 51(1), 81-89.

Mitchell, S. A., Oslin, J. L., \& Griffin, L. L. (1995). The effects of two instructional approaches on game performance. Pedagogy in Practice, 1(1), 36-48.

Mitchell, S. A., Oslin, J. L., \& Griffin, L. L. (2006). Teaching Sports Concepts and Skills: A Tactical Games Approach (2a ed.). Champaign: Human Kinetics.

Morgan, D. L. (1996). Focus group. Annual Review of Sociology, 22(1), 129-152 doi:10.1146/annurev.soc.22.1.129

Morgan, D. L. (1997). Focus groups as qualitative research (2a ed.). Thousand Oaks, CA: Sage. doi:10.1146/annurev.soc.22.1.129

Oslin, J. L., Mitchell, S. A., \& Griffin, L. L. (1998). The Game Performance Assessment Instrument (GPAI): Development and preliminary validation. Journal of Teaching in Physical Education, 17(2), 231-243.

Patton, K. G. (2006). The Effects of a Teacher Induction Program on Graduate Student Teacher Efectiveness in Physical Education (Tesis doctoral). The Florida State University, Estats Units d'Amèrica.

Ruiz, L. M. \& Arruza, J. (2005). El proceso de toma de decisiones en el deporte: Clave de la eficiencia y el rendimiento óptimo. Barcelona: ediciones Paidós Ibérica S.A. 